\title{
EFEKTIVITAS PROGRAM ASISTENSI SOSIAL PENYANDANG DISABILITAS BERAT (ASPDB) DI KOTA BANDAR LAMPUNG
}

\author{
Yuyun Fitriani \\ Jurusan Ilmu Administrasi Negara, STISIPOL Dharma Wacana \\ *Korespondensi: yuyunfitriani01.yf@gmail.com
}

\begin{abstract}
The Social Assistance Program for Persons with Severe Disabilities (ASPDB) is a form of state responsibility in fulfilling the rights of persons with disabilities and the embodiment of government social protection for its citizens. The target group of the ASPD program are people with severe disabilities who are unable to carry out activities to fulfill their daily lives so they need help from others. Measurement of effectiveness criteria is based on three main objectives of implementing the ASPDB program, namely: First, the fulfillment of the basic needs of life and daily care for persons with severe disabilities (clothing, food, clean water, daily care) so that their welfare level can be met fairly. Second, the growing concern of families and communities in providing social care and guidance for persons with severe disabilities. Third, growing efforts to fulfill the rights of persons with severe disabilities. Broadly speaking, the effectiveness of the implementation of the ASPDB program in Bandar Lampung has been well implemented. Families of persons with disabilities, which are the main milestones for the growth and development of persons with disabilities, have skills in caring for and looking after persons with disabilities. The community in the neighborhood where persons with disabilities live also do not discriminate against the existence of persons with disabilities so that persons with disabilities can play and interact with the community. Families of persons with disabilities, which are the main milestones for the growth and development of persons with disabilities, have skills in caring for and looking after persons with disabilities. The community in the neighborhood where persons with disabilities live also do not discriminate against the existence of persons with disabilities so that persons with disabilities can play and interact with the community. Families of persons with disabilities, which are the main milestones for the growth and development of persons with disabilities, have skills in caring for and looking after persons with disabilities. The community in the neighborhood where persons with disabilities live also do not discriminate against the existence of persons with disabilities so that persons with disabilities can play and interact with the community.
\end{abstract}

Keywords: Effectiveness, Social Assistance Program for Persons with Severe Disabilities (ASPDB), Disabilities Person.

\begin{abstract}
Abstrak
Program Asistensi Sosial Penyandang Disabilitas Berat (ASPDB) adalah bentuk pertanggungjawaban negara dalam pemenuhan hak-hak penyandang disabilitas dan perwujudan dari perlindungan sosial pemerintah terhadap warganya. Kelompok sasaran program ASPD adalah penyandang disabilitas berat yang tidak mampu melakukan aktivitas pemenuhan hidupnya sehari-hari sehingga membutuhkan pertolongan orang lain. Pengukuran kriteria efektivitas didasarkan pada tiga tujuan utama pelaksanaan program ASPDB yakni: Pertama, terpenuhinya kebutuhan dasar hidup dan perawatan sehari-hari penyandang disabilitas berat (sandang, pangan, air bersih, perawatan sehari hari) agar taraf kesejahteraan
\end{abstract}


hidupnya dapat terpenuhi secara wajar. Kedua, tumbuhnya kepedulian keluarga dan masyarakat dalam melakukan perawatan dan bimbingan sosial bagi penyandang disabilitas berat. Ketiga, tumbuhnya upaya-upaya pemenuhan hak-hak penyandang disabilitas berat. Secara garis besar efektivitas pelaksanaan program ASPDB di Kota Bandar Lampung telah dilaksanakan dengan baik. Keluarga penyandang disabilitas yang merupakan tonggak utama tumbuh kembang penyandang disabilitas memiliki keterampilan dalam mengurus dan menjaga penyandang disabilitas. Masyarakat di lingkungan sekitar tempat tinggal penyandang disabilitas juga tidak mendiskriminasi keberadaan penyandang disabilitas sehingga para penyandang disabilitas dapat bermain dan berinteraksi dengan masyarakat.

Kata Kuci: Efektivitas, Penyandang Disabilitas, Program Asistensi Sosial Penyandang Disabilitas

\section{PENDAHULUAN}

Tulisan ini mengurai tentang tanggung jawab pemerintah melindungi dan mensejahterakan penyandang disabilitas berat dalam rangka mewujudkan keadilan sosial bagi seluruh rakyat Indonesia sebagaimana diamanatkan Pancasila dan UndangUndang Dasar Negara Republik Indonesia Tahun 1945. Kesejahteraan sosial diatur dalam Undang-Undang Nomor 11 Tahun 2009 tentang Kesejahteraan Sosial yang menyatakan bahwa penyelenggaraan kesejahteraan sosial adalah upaya yang terarah, terpadu dan berkelanjutan yang dilakukan pemerintah, pemerintah daerah dan masyarakat dalam bentuk pelayanan sosial guna memenuhi kebutuhan dasar setiap warga negara, yang meliputi rehabilitasi sosial, pemberdayaan sosial, dan perlindungan sosial. Kesejahteraan sosial juga termasuk sebagai suatu proses atau usaha terencana yang dilakukan oleh perorangan, lembaga-lembaga sosial, masyarakat maupun badan-badan pemerintah untuk meningkatkan kualitas kehidupan melalui pemberian pelayanan sosial dan tunjangan sosial (Suharto, 2008). Merujuk pada data Survei Penduduk Antar Sensus (SUPAS) 2015 jumlah penyandang disabilitas menurut Direktorat Orang Dengan Kecacatan Kementerian SosiaI Republik Indonesia adalah 3.838.985 jiwa.
Upaya perlindungan disabilitas yang meliputi rehabilitasi sosial, pemberdayaan sosial, dan perlindungan sosial termuat dalam Undang-Undang Nomor 8 Tahun 2016 tentang Penyandang Disabilitas. Menurut Undang-undang tersebut penyandang disabilitas adalah setiap orang yang mengalami keterbatasan fisik, intelektual, mental, dan/atau sensorik dalam jangka waktu lama yang dalam berinteraksi dengan lingkungan dapat mengalami hambatan dan kesulitan untuk berpartisipasi secara penuh dan efektif dengan warga negara lainnya berdasarkan kesamaan hak. Sebagai upaya perlindungan disabilitas pemerintah membentuk program Asistensi Sosial bagi Penyandang Disabilitas Berat (ASPDB) yang merupakan bentuk pertanggungjawaban negara dalam pemenuhan hak-hak penyandang disabilitas dan perwujudan dari perlindungan sosial pemerintah terhadap warganya. Kelompok sasaran program ASPDB adalah disabilitas berat yang tidak dapat direhabilitasi dan penyandang tidak mampu melakukan kegiatan sehari-hari seperti makan, minum, dan mandi, sehingga membutuhkan bantuan orang lain. Mereka tidak mampu dan tidak memiliki sumber penghasilan tetap baik dari mereka sendiri maupun dari orang lain untuk memenuhi kebutuhan dasar. Keluarga menjadi landasan bagi kehidupannya karena mereka tidak 
dapat mengakses layanan utama seperti program perawatan kesehatan dan distribusi permakanan, karena hambatan fisik. Bantuan pemerintah diharapkan dapat mengurangi beban keluarga untuk mengasuh dan merawat anggota yang menyandang disabilitas.

Penanganan orang dengan kecacatan berat dengan perlindungan sosial melalui jaminan sosial telah dilakukan sejak tahun 2006 sampai dengan 2010 dengan nama JSPACA/JSODKB. Mulai tahun 2011 sampai saat ini, bantuan untuk orang dengan kecacatan berat yang semula bernama JSODKB berubah menjadi ASPDB dan sudah menjadi program prioritas nasional berdasarkan Inpres No. 3 tahun 2010 tentang program pembangunan yang berkeadilan dan Instruksi Presiden Nomor 14 Tahun 2011 tentang Percepatan Pelaksanaan Prioritas Pembangunan Nasional Tahun 2011. Penyandang disabilitas yang mendapatkan program ASPDB ini adalah penyandang disabilitas yang berusia antara 2 tahun sampai 59 tahun.

Penyandang Disabilitas dibanding dengan warga non-penyandang disabilitas, dalam hal pelayanan dasar, seperti pendidikan dan pekerjaan, dan pelayanan sosial lainnya, masih jauh tertinggal. Laporan BPS hasil SUPAS tahun 2015, dan Laporan Survey Sosial dan Ekomomi Nasional (SUSENAS) tahun 2017 menyebutkan bahwa lebih dari $90 \%$ Penyandang Disabilitas usia di bawah 25 tahun hanya berpendidikan Sekolah Dasar. Di bidang pekerjaan, Penyandang Disabilitas cenderung bekerja di sektor non-formal dibandingkan pekerjaan sektor formal. Keterbatasan aksesibilitas tempat kerja, menjadi alasan mereka memilih sektor non-formal (Kasim, 2015)

Selain pemeuhan hak penyandang disabilitas yang masih sangat terbatas, kompetensi berupa pengetahuan, keterampilan dan sikap dalam mengasuh dan merawat PDB masih kurang memadai. Hal ini terungkap dari sebagian besar keluarga belum memberikan pengasuhan dan perawatan kesehatan secara spesifik sesuai kebutuhan PDB, seperti terapi, pemberian makan, vitamin, susu, dll. Pengetahuan dan sikap keluarga dalam memberikan kasih sayang dan perhatian terhadap PDB sudah cukup memadai. Terkait dengan rendahnya keterampilan keluarga dalam pengasuhan dan perawatan kesehatan dapat berpengaruh pada pemenuhan kebutuhan akan perawatan dan kesehatan (Murni \& Astuti, 2017).

Berdasarkan data yang dipublish dalam website Badan Pusat Statisitik Kota Bandar Lampung (https:// lampung .bps.go.id) jumlah penyandang disabilitas di Kota Bandar Lampung mencapai 1.150 Jiwa. Jumlah tersebut bukanlah jumlah yang sedikit sehingga artikel ini akan mengulas efektivitas program Asistensi Sosial Penyangdang Disabilitas Berat (ASPDB) Di Kota Bandar Lampung.

\section{METODE}

Tulisan ini berangkat dari metode penelitian kualitatif dengan pendekatan deskriptif. pendekatan deskriptif menggambarkan suatu fenomena yang ada dengan jalan memaparkan data secara kata-kata dan gambar (Moleong, 2007). Pengumpulan data dilakukan melalui kegiatan wawancara dengan keluarga penyandang disabilitas berat yang menerima program ASPDB di Kota Bandar Lampung. Metode penelitian kualitatif memiliki kelebihan data deskriptif lebih detail dan mendalam; data menggambarkan pandangan realistis terhadap dunia sosial yang dialami oleh subjek penelitian yang tidak bisa diukur 
secara numerik; memberika kesempatan pada partisipan untuk mendeskripsikan perspektifnya terhadap fenomena yang diteliti; proses pengumpulan data dilakukan secara fleksibel sesuai dinamika di lapangan; interaksi dilakukan dengan bahasa partisipan sehari-hari, dengan terminologi khas yang mereka gunakan; dan fokus riset selalu merespon pada perubahan yang terjadi selama proses penelitian, tidak memaksakan pandangan peneliti yang disusun sebelumnya di atas meja.

\section{HASIL DAN PEMBAHASAN}

Pada kegiatan evaluasi, penekanan kriteria ini terletak pada pencapaian hasil. Apakah hasil yang diinginkan dari adanya suatu kebijakan sudah tercapai. Menurut Dunn (2003) dan Suharno (2013) efektivitas berhubungan dengan rasionalitas teknis, selalu diukur dari unit produk atau layanan atau nilai moneternya.

Terpenuhinya kebutuhan dasar hidup dan perawatan sehari-hari penyandang disabilitas berat (sandang, pangan, air bersih, perawatan sehari hari) agar taraf kesejahteraan hidupnya dapat terpenuhi secara wajar.

Pemenuhan hak penyandang disabilitas berat oleh Pemerintah, dilaksanakan dalam bentuk Asistensi Sosial bagi Penyandang Disabilitas Berat (ASPDB) dengan pemberian bantuan langsung berupa uang tunai sebesar Rp. 300.000,- per orang per bulan selama 1 (satu) tahun, yang penyalurannya dilaksanakan dalam 3 (tiga) tahap. Bantuan disampaikan melalui wali (individu yang bertanggungjawab menjamin hidup Penyandang Disabilitas Berat dalam rangka pemenuhan kebutuhan makanan, peningkatan gizi, pembelian sandang, dan perawatan sehari-hari.

Salah satu tujuan program ASPDB adalah terpenuhinya kebutuhan dasar hidup dan perawatan sehari-hari penyandang disabilitas berat (sandang, pangan, air bersih, perawatan seharihari) agar taraf kesejahteraan hidupnya dapat terpenuhi secara wajar telah dilakukan dengan baik oleh wali/keluarga penyandang disabilitas yakni dengan membelanjakan uang tunai bantuan ASPBD dengan membelikan keluarga mereka kursi roda, pempers, peralatan sekolah, obatobatan dan lain-lain. Keluarga Abel, Witriyani dan gunawan menggunakan uang ASPDB untuk membeli kursi roda, keluarga Asih untuk membeli pempers.

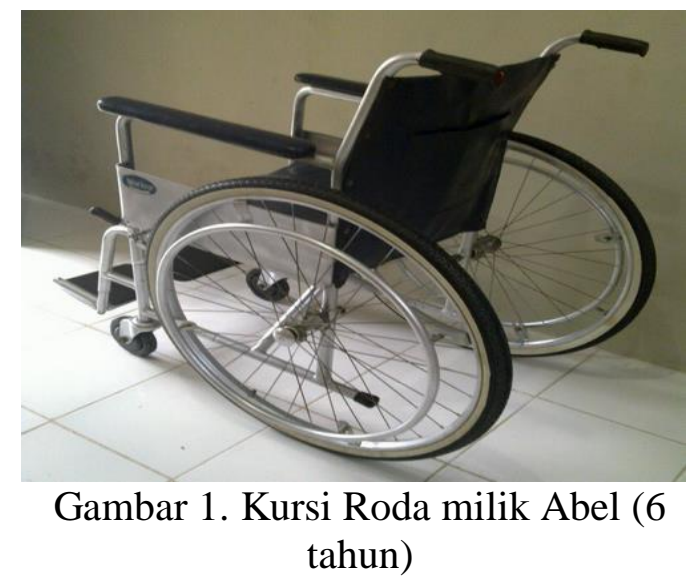

Sumber: Dokumentasi penelitian, 2016.

Penggunaan uang bantuan program ASPDB dengan membeli kursi roda merupakan pilihan terbaik karena penyandang disabilitas mengalami kelumpuhan. Kursi roda dapat digunakan penyandang disabilitas untuk kegiatan diluar rumah, seperti melihat teman-teman bermain. Selain itu penggunaan uang bantuan program ASPDB juga dibelikan pampers oleh beberapa anggota keluarga penyandang disabilitas. 


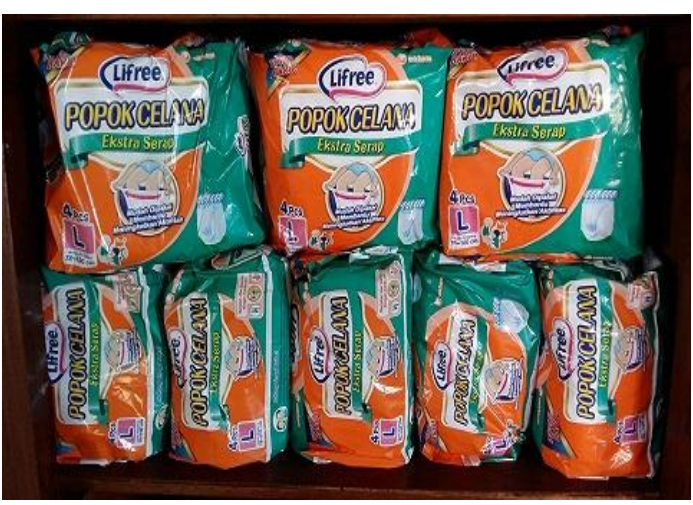

Gambar 2. Popok sekali pakai yang digunakan oleh Asih (12 tahun)

Sumber: Dokumentasi penelitian, 2016.

Popok sekali pakai merupakan kebutuhan utama bagi penyandang disabilitas terutama yang mengalami kelumpuhan untuk menjaga kebersihan tubuhnya. Selain itu, penggunaan pampers juga dapat meminimalisir kegiatan keluarga penyandang disabilitas untuk mengantar ke kamar mandi penyandang disabilitas itu sendiri.

Di Kota Bandar Lampung sendiri penyaluran program ASPDB sudah tepat sasaran. Pemenuhan hak-hak dasar seperti sandang, pangan, dan papan bagi penyandang disabilitas berat dapat dilakukan dengan dana bantuan yang diberikan oleh pemerintah. Meskipun nominalnya cukup kecil namun cukup membantu untuk pemenuhan kebutuhan sehari-hari penyandang disabilitas berat.

Tumbuhnya kepedulian keluarga dan masyarakat dalam melakukan perawatan dan bimbingan sosial bagi penyandang disabilitas berat.

Peran keluarga sangat penting dalam menangani permasalahan orang dengan kecacatan, khususnya orang dengan kecacatan berat. Mengadop pada sebuah penelitian tentang peran pentingnya pengasuhan (caregiver) pada pasien berpenyakit kronis yang karakteristiknya hampir sama dengan disabilitas berat bahwa kompetensi keluarga pengasuh menainkan peranan penting dalam proses perawatan pada pasien (Reinhard et al., 2008). Keluarga sebagai unit terkecil dalam masyarakat memegang peranan penting dalam upaya meningkatkan kesejahteraan masyarakat yang lebih lanjut diharapkan mengurangi timbulnya masalah-masalah sosial (Gunarsa \& Gunarsa, 1993 dalam Setiawan et al, 2017)

Perawatan penyandang disabilitas berat secara menyeluruh menjadi tanggung jawab keluarga, terutama orangtua. Respon keluarga terutama orang tua terhadap anggota keluarganya yang PDB tidak selalu positif, bahkan mungkin malu memiliki anak PDB, hal ini akan menimbulkan PDB kehilangan hak-haknya. Seperti yang tertulis dalam Rangkuman Eksekutif Keadaan Anak Di Dunia, tentang Anak Disabilitas oleh UNICEF tahun 2013, yang diterjemahkan oleh Riyanto bahwa anak-anak penyandang disabilitas seringkali terperangkap dalam siklus kemiskinan dan pengucilan. Anak perempuan terpaksa menjadi pengasuh adik-adiknya, bukan pergi ke sekolah misalnya, atau seluruh keluarga mengalami stigmatisasi sehingga enggan untuk melaporkan, bahwa ada anak penyandang disabilitas atau enggan membawanya ke publik (dalam Murni \& Astuti, 2017).

Penyandang

memerlukan tenaga pendamping (caregiver) untuk memberikan pelayanan secara terus menerus. Dalam upaya untuk memenuhi kebutuhan pelayanan kepada penyandang disabilitas, sudah seharusnya sebagai pendamping, orang tua mengambil peranan penting dalam memberikan pelayanan dengan tepat, penuh tanggung jawab, dan penuh kasih sayang. Kompetensi sebaiknya dimiliki oleh orang tua/ anggota keluarga sebagai pendamping bagi anggota 
keluarganya yang mengalami disabilitas berat. Adapun yang dimaksud kompetensi orang tua atau anggota keluarga yang menjadi pendamping anak atau anggota keluarganya yang mengalami disabilitas berat, adalah pengetahuan, keterampilan dan sikap (attitude). Pertama, pengetahuan ini mencakup tentang kedisabilitasan yakni cara merawat penyandang disabilitas, bagaimana akses yang bisa didapat dari pemerintah, dan program-program yang disediakan oleh pemerintah. Kedua, keterampilan berkaitan dengan cara merawat anak atau anggota keluarga yang mengalami disabilitas berat. Keterampilan dapat berupa kemampuan merawat penyandang disabilitas secara fisik dengan baik dan kemampuan membesarkan hati penyandang disabilitas dengan terus memberikan motivasi. Tidak sedikit anggota keluarga yang serumah baik secara sosial maupun psikologis belum / tidak siap menerima anggota keluarganya yang penyandang disabilitas, bahkan ada yang melakukan penolakan terhadap kehadirannya. Ketiga, sikap dan nilai (attitude and value) kesabaran dan keikhlasan sangat diperlukan, karena kondisi keterbatasan yang disandang penyandang disabilitas membutuhkan pelayanan sesuai dengan kemampuan, menerima kondisi sebagaimana adanya, serta ikhlas dalam menjalankan tugas merupakan suatu bentuk sikap ingin membantu tanpa memikirkan imbalan. Rasa empati, dengan turut merasakan apa yang dirasakan dan menempatkan diri pada kesulitan yang dialami penyandang disabilitas. Dengan menolong akan melahirkan sikap mengasihi antar sesama, saling mengasihi, serta memperhatikan akan melahirkan kedamaian bagi penyandang disabilitas.
Tumbuhnya upaya-upaya pemenuhan hak-hak penyandang disabilitas berat

Rendahnya

masyarakat terhadap masalah disabilitas, Stigma (kutukan, nasib), isolasi dan perlindungan yang berlebihan, kurangnya peran keluarga dan masyarakat terhadap masalah disabilitas dan penanganannya, kurangnya upaya pemenuhan hak-hak penyandang disabilitas dalam berbagai aspek kehidupan, masih banyaknya penyandang disabilitas yang hidup di bawah garis kemiskinan dan tingkat pendidikan masih sangat rendah, masih banyaknya keluarga penyandang disabilitas yang menyembunyikan atau menutupi bila memiliki anggota keluarga disabilitas dan peran dunia usaha belum maksimal (Diono, 2014).

Berdasarkan Undang-Undang Republik Indonesia Nomor 8 Tahun 2016 Tentang Penyandang Disabilitas Pasal 5 ayat (1) Penyandang Disabilitas memiliki hak: a) hidup; b) bebas dari stigma; c) privasi; d) keadilan dan perlindungan hukum; e) pendidikan; f) pekerjaan, kewirausahaan, dan koperasi; g) kesehatan; h) politik; i) keagamaan; j) keolahragaan; k) kebudayaan dan pariwisata; 1) kesejahteraan sosial; $\mathrm{m}$ ) Aksesibilitas; n) Pelayanan Publik; o) Pelindungan dari bencana; p) habilitasi dan rehabilitasi; q) Konsesi; r) pendataan; s) hidup secara mandiri dan dilibatkan dalam masyarakat; t) berekspresi, berkomunikasi, dan memperoleh informasi; u) berpindah tempat dan kewarganegaraan; dan v) bebas dari tindakan Diskriminasi, penelantaran, penyiksaan, dan eksploitasi.

Realitanya pemenuhan hak-hak penyandang disabilitas masih sangat terbatas. Penyandang disabilitas belum memiliki tingkat pendidikan yang baik dan seringkali masih mendapat stigma 
buruk dari masyarakat umum. Melalui program ASPDB dan penumbuhkembangan Sekolah Luar Biasa (SLB) yang dikhususkan bagi penyandang disabilitas diharapkan dapat meningkatkan taraf hidup penyandang disabilitas melalui peningkatan pendidikan.

\section{Penutup}

Program ASPDB diberikan tepat kepada penyandang disabilitas berat di Kota Bandar Lampung. Efektivitas pelaksanaan program ASPDB di Kota Bandar Lampung belum tercapai dengan baik. Hal tersebut disebabkan oleh hanya pemenuhan kebutuhan pokok penyandang disabilitas yang dapat terpenuhi dengan pemberian dana bantuan ASPDB. Sementara itu, kemampuan keluarga penyandang disabilitas untuk melakukan perawatan belum baik dan hak-hak penyandang disabilitas belum terpenuhi.

\section{DAFTAR PUSTAKA}

Diono, A. 2014. Program Rehabilitasi Sosial Penyandang Disabilitas dan Pergeseran Paradigma Penanganan Penyandang Disabilitas. Buletin Jendela Data \& Informasi Kesehatan, Semester 2 Tahun 2014.

Dunn, W. (2003). Pengantar Analisis Kebijakan Publik. Yogyakarta: Gadjah Mada University Press.

Kasim, E. R. (2019). Quo Vadis Kesejahteran Sosial Penyandang Disabilitas Pasca Undang-Undang No. 8 Tahun 2016. Jurnal Analis Kebijakan, 3(1) Tahun 2019.

Moleong, L. J. (2007). Metodologi Penelitian Kualitatif. Edisi Revisi. Bandung: PT Remaja Rosdakarya.

Murni, R. \& Astuti, M. (2017). Kondisi Keluarga Penerima Asistensi
Sosial Penyandang Disabilitas Berat. Jurnal PKS, 16(3), September 2017; $295-310$.

Reinhard, S. C., Given, B., Petlick, N. H., Bemis, A. (2008). Supporting Family Caregivers in Providing Care. In Hughes, R. G (editor). (2008). Patient Safety and Quality: An Evidence-Based Handbook for Nurses. Rockville (MD): Agency for Healthcare Research and Quality (US).

Setiawan, H. H. et al. (2017). Pengaruh Dukungan Ekonomi Keluarga dan Kompetensi Keluarga terhadap Pemenuhan Hak Penyandang Disabilitas Berat. Sosio Konsepsia, 6(02), Januari - April, Tahun 2017.

Suharno. 2013. Dasar-dasar Kebijakan Publik. Yogyakarta. Penerbit Ombak

Suharto, Edi. 2008. Kebijakan Sosial Sebagai Kebijakan Publik. Bandung: Alfabeta.

Undang-Undang Republik Indonesia Nomor 8 Tahun 2016 Tentang Penyandang Disabilitas 